\title{
Environmental assessment of soil pollution by heavy metals within the boundaries of roadside areas
}

\author{
Ekaterina Antonenko ${ }^{1, *}$, Aleksandr Melnichuk ${ }^{1}$, and Valentina Popovich ${ }^{2}$ \\ ${ }^{1}$ V.I. Vernadsky Crimean Federal University, Simferopol, 295492, Russia \\ ${ }^{2}$ FSBSI "Research Institute of Agriculture of Crimea", Simferopol, 295493, Russia
}

\begin{abstract}
The work is devoted to the environmental assessment of degree of soil pollution with heavy metals on land plots, located within the boundaries of roadside territories. The study area is characterized by uneven anthropogenic load on different sections of the road. The article examines the indicator of lands ecological state, taking into account heavy metals content, their toxicity, excess of background level. As a result of the research, it was revealed that the excess of the MPC was recorded for two elements of the 1st hazard class - lead and zinc. Thus, the 5-meter zone belongs to the category of very strong pollution (2 MPC for lead, 1 MPC for zinc, and the zone from 25 to $50 \mathrm{~m}$ is slightly contaminated). This algorithm can be used for an integral and ecological-economic assessment of soils of land plots, located within the boundaries of roadside territories.
\end{abstract}

\section{Introduction}

One of the important factors of soil degradation is technogenic pollution, caused by the influence of both stationary sources and traffic flow of highways. The presence of heavy metals high concentrations in soils clearly reflects the degree of technogenic pollution of urbanized areas. Soil is good accumulator, capable of storing heavy metals. Being in soils, these chemical elements and their compounds, together with dust, enter the respiratory system, and with food and water into other human organs. Emissions from vehicles contain a large amount of ecotoxicants that belong to hazard class 1: 3,4-benz(a)pyrene, arsenic, cadmium, mercury, lead, zinc, etc [1].

In the Republic of Crimea, roadside territories are represented mainly by agricultural lands, as well as lands of settlements, in which residential buildings are close enough to the road, which negatively affects people's health. Therefore, it is very important to establish, assess and take into account the ecological state of the lands, bordering the motorways.

Distribution of heavy metals on the soil surface depends on characteristics of pollution source, meteorological specifics of the region, geochemical factors and landscape situation in general. Most often, in the soils of roadside landscapes, an increased content of lead is recorded, which is one of the most toxic elements. But in connection with the ban on leaded fuels use, the problem of lead contamination of roadside space is no longer relevant.

*Corresponding author: antonenkatrina87@gmail.com 
According to V.N. Pshenin geochemical anomalies of zinc are formed along highways as a result of tire wear, abrasion of brake pads and other parts with anti-corrosion coating. Unlike lead, zinc is more mobile, therefore, it moves more easily along the soil profile, it is absorbed by plants and migrates into aquatic environment $[2,3]$.

Modern studies, related to the impact of traffic on the content of heavy metals in the soil cover, are carried out by ecologists, doctors, economists, etc. Topic of scientific works has changed with the development of the car-building and petrochemical industries. Previously, most researchers were studying the effect of lead on environment and human health [4-8]; today, a formidable carcinogenic ecotoxicant $-3,4$ benzopyrene, has been added to it [9-11]. Since harmful substances not only accumulate in soil, but also migrate, entering the water and are absorbed by plants, the problem of comprehensive assessment of heavy metals content in the soil cover of roadside territories remains urgent.

The study purpose is to determine the level of heavy metal contamination of roadside lands. To achieve this goal, the following tasks have been set: - to consider the features of roadside areas of motor roads of the Republic of Crimea; - calculate the total coefficient of technogenic pollution; - based on the results obtained, zoning the territory according to the level of pollution.

\section{Location and method}

\subsection{Time and location}

Roadside territories are land plots (their parts), adjacent to the roadside strip or the outlet strip, which affects the transport stream of the automotive road. Land plots located in this zone are not burdened with a special regime of land use, but constantly experiencing the negative impact of the automotive road - as a source of environmental pollution [12]. The roadside territories of the main highways of the Republic of Crimea (Figure 1) are differ in their intended purpose by heterogeneous structure of lands.

In the steppe regions, where the roads Simferopol - Saki, Simferopol - Dzhankoy, as well as the federal highway "Tavrida" pass, agricultural land plots prevail as part of lands (more than $50 \%$ ), the share of land plots for industry, energy, transport, etc. is $15-30 \%$, and the share of settlements lands varies from 9 to $28 \%$. In the mountain-forest zone (the SimferopolAlushta highway), $50 \%$ falls on the lands of settlements and more than $25 \%$ falls on forest fund lands of. In addition, roadside landscapes are subject to different anthropogenic impacts, which is primarily associated with the intensity of car traffic, it can range from 1 thousand vehicles/hour to 1600 or more vehicles/hour. Thus, residential buildings are located in the zone of active influence of highways, which can negatively affect people's health.

The study object is the federal highway "Tavrida" section in the direction of Simferopol - Bakhchisarai, the length of which is $32 \mathrm{~km}$. The structure of roadside territories is dominated by agricultural lands $(42 \%)$, lands of settlements $(28 \%)$, lands for industry, energy, transport, etc. (30\%) (Figure 2). 

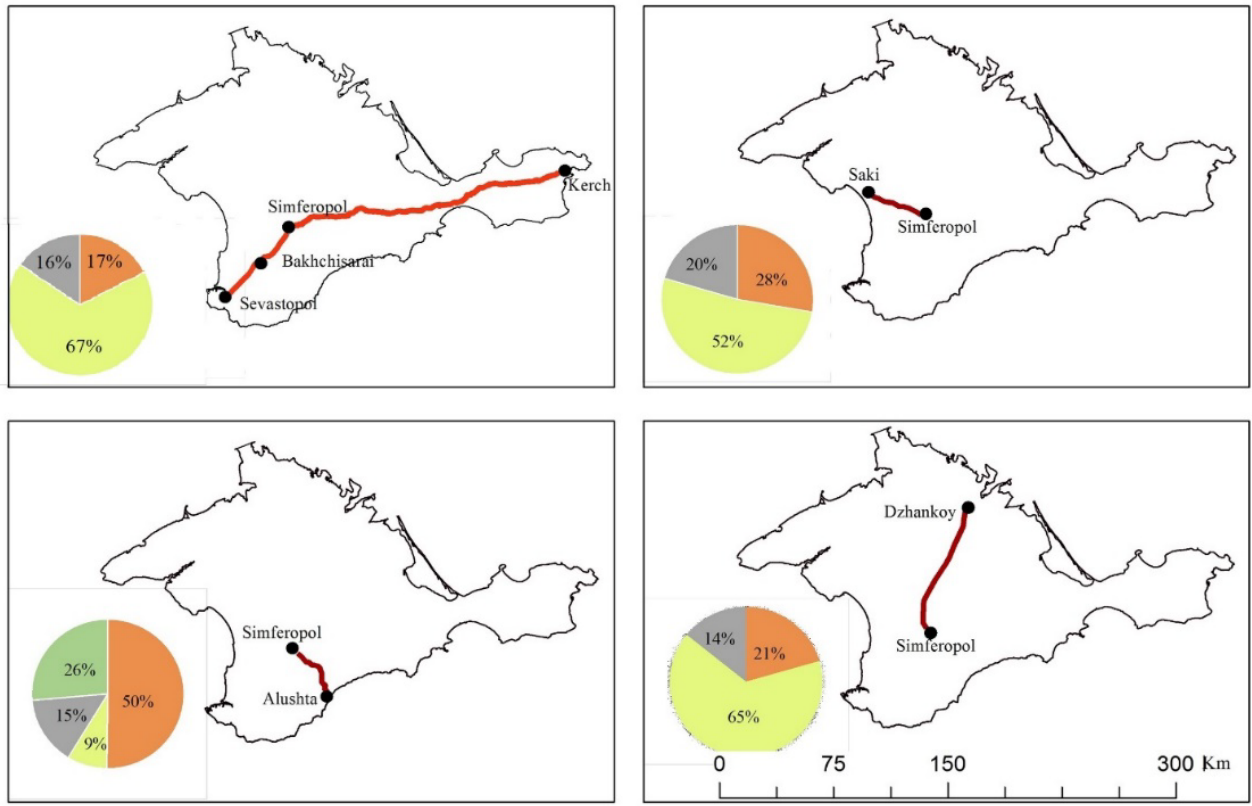

Legend

Borders of Crimean peninsula

- Tavrida federal highway

Roads of regional importance

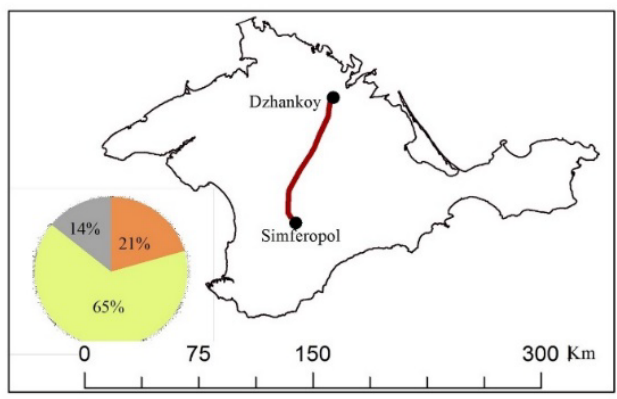

Land categories for purpose

Agricultural land

Land of settlements

Industrial land, energy, transport, etc.

Land of the Forest Foundation

Fig. 1. Land structure of roadside areas along auto roads in the Republic of Crimea.

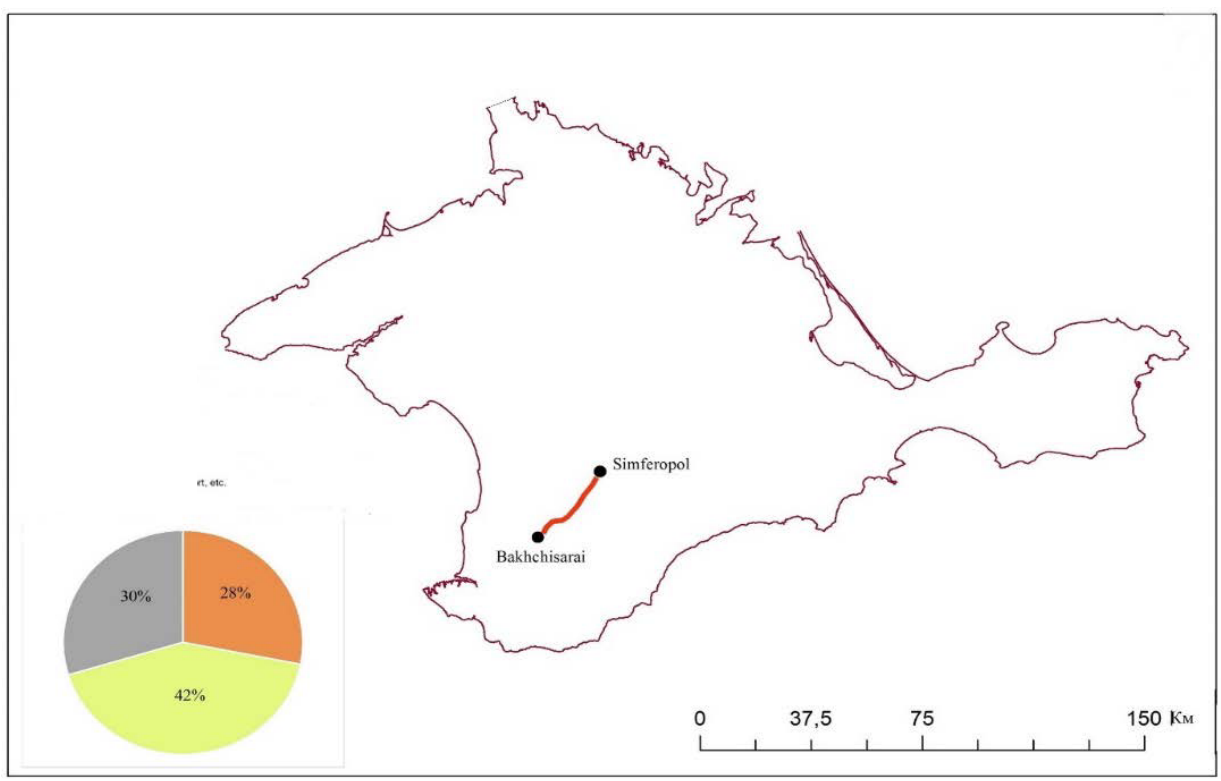

Fig. 2. The structure of roadside lands on the «Tavrida» federal highway section.

Field measurements were carried out in the area of v. Priyatnoye svidanie. The structure of vehicles with different types of engines is dominated by cars ( $60 \%$ of car traffic) and trucks 
with different carrying capacity (30\%), traffic intensity - 1629 vehicles / hour. Soil sampling was carried out by the envelope method at a distance of 5,25 and $50 \mathrm{~m}$ from the road.

Pollutants spreading is largely related to the direction of prevailing winds. According to the Federal State Budgetary Institution "Crimean Department of Hydrometeorology and Environmental Monitoring" the prevailing wind directions for the territory of the Bakhchisarai region (meteorological station is in v. Pochtovoe) are east (35\%) and north-east $(22 \%)$ (Figure 3.).

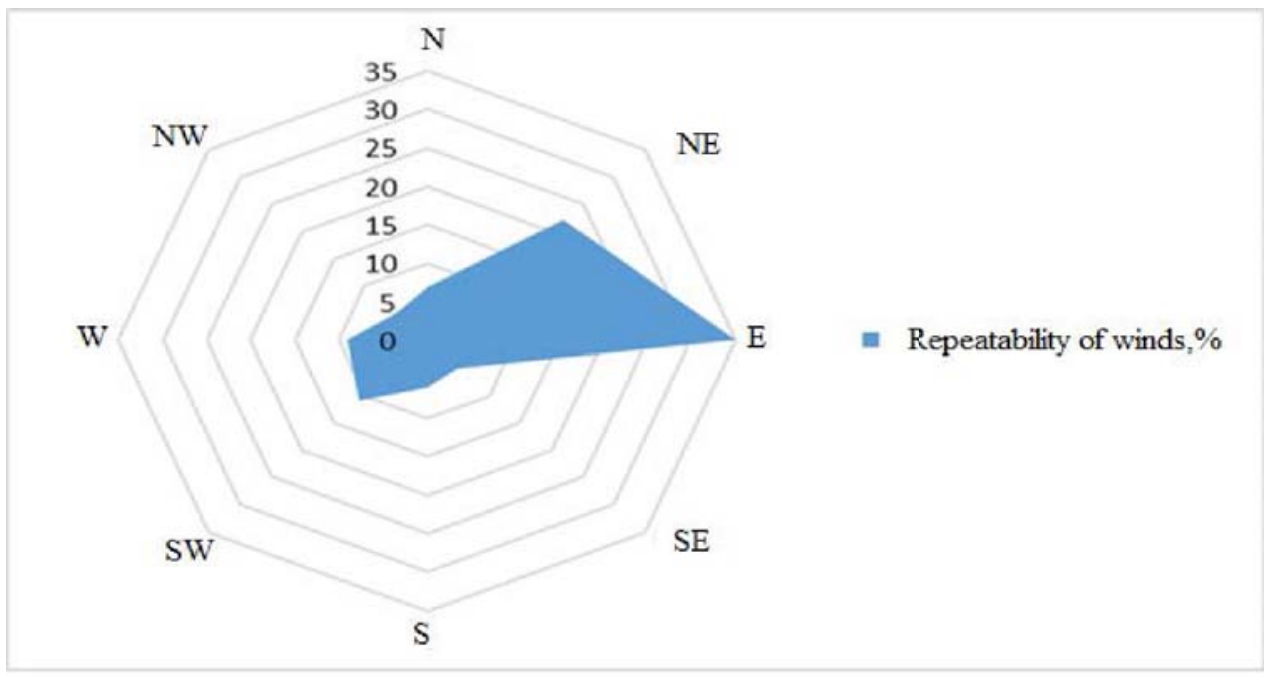

Fig. 3. Repeatability of wind directions for $2020, \%$.

The prevalence of east and north-east winds contributes to the pollutants spread into the residential area on the right side of the highway (towards the city of Bakhchisarai).

\subsection{Method}

Several indicators of soil pollution are currently used in the Russian Federation [13]. If the soil is contaminated with one inorganic substance, then when assessing it, hazard class, maximum permissible concentrations (MPC) and maximum level of pollutant harmfulness are taken into account. To assess the level of soils chemical pollution with several elements, the pollutant concentration coefficient $(\mathrm{Kc})$ is used, which is calculated by the formula (1):

$$
K_{c}=\frac{C_{i}}{C_{f i}},
$$

where $K_{c}$ - pollutant concentration coefficient; $C_{i}$ - content of the pollutant in the given soil, $\mathrm{mg} / \mathrm{kg} ; C_{f i}=$ background content of the pollutant.

Such integral indicator as the total coefficient of technogenic pollution $\left(Z_{c}\right)$ is widely used (formula (2)):

$$
Z_{c}=\sum_{i=1}^{N} K_{c_{i}}-(n-1)
$$

where $K_{c_{i}}$ - concentration factor of the $i$-th component of pollution; $n$ - number of defined summed substances. 
Another integral indicator, proposed in [14,15], which takes into account differences in the toxicity of elements, was used in the work. To assess the environmental pollution of soils in points, the formula (3) was applied:

$$
D=\sum_{i=1}^{N}\left(\frac{C_{i}}{C_{i f}}\right) \times K_{i}
$$

where $D$ - total concentration factor; $C_{i}$ - content of the element in the studied soil, $\mathrm{mg} / \mathrm{kg}$; $C_{i f}$ - background content of the element, $\mathrm{mg} / \mathrm{kg} ; K_{i}$ - coefficient of significance of elements and compounds, is inversely proportional to the MPC (APC).

$$
\text { If } C_{i} \leq C_{i f} \text {, then } \frac{C_{i}}{C_{i f}} \rightarrow 1
$$

The integral assessment score is calculated by the formula (5):

$$
B=\frac{D_{f} \times 100}{D}
$$

where $\mathrm{B}=$ integral estimated score $(0-100) ; D=$ total concentration factor; $D_{f}=$ reduced total concentration factor for the background soil (the estimated score is 100).

$$
D_{f}=\sum_{i=1}^{N} K_{i},
$$

where $K_{i}=$ significance coefficient of elements and compounds.

\section{Results and discussion}

Based on the results of determining the mobile forms of chemical substances, an elemental series of accumulation of heavy metals in the soils of roadside territories at the experimental site (village Priyatnoye Svidanie) was established: $\mathrm{Zn}>\mathrm{Pb}>\mathrm{Cu}>\mathrm{Co}>\mathrm{Cd}>\mathrm{Fe}$ (Figure 3).

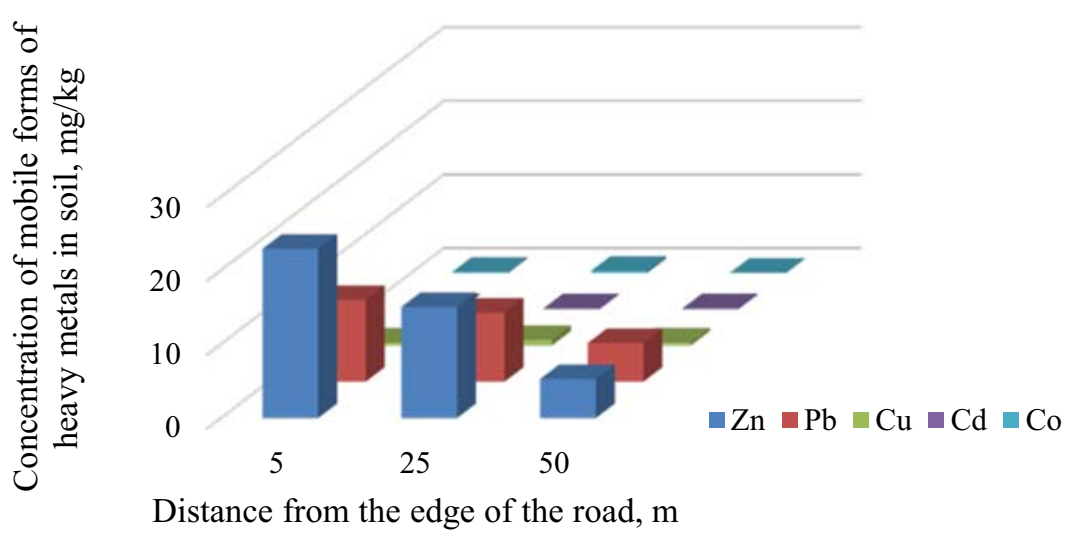

Fig. 3. Changes in the concentration of heavy metals, taking into account the distance from the source of pollution.

Initial data for calculating indicators of environmental pollution of roadside areas are presented in Table 1. 
Table 1. The content of heavy metals in the soil cover of roadside areas, taking into account the distance from the source of pollution.

\begin{tabular}{|c|c|c|c|c|c|c|}
\hline No. of sites & Zn & Pb & Cu & Cd & Co & Fe \\
\hline $1(0-5 \mathrm{~m})$ & 22.9 & 12.0 & 0.4 & 0.2 & 0.2 & $<0.1$ \\
\hline $2(5-25 \mathrm{~m})$ & 15.0 & 9.3 & 0.8 & 0.1 & 0.3 & $<0.1$ \\
\hline $3(25-50 \mathrm{~m})$ & 5.3 & 5.2 & 0.4 & 0.1 & 0.1 & $<0.1$ \\
\hline Background & 6.1 & $<5.0$ & $<2.0$ & $<0.2$ & $<2.0$ & $<0.1$ \\
\hline MPC & 23.0 & 6.0 & 5.0 & - & 5.0 & - \\
\hline
\end{tabular}

The indicators of environmental pollution of the territory were calculated according to formulas $(2,5)$ at different distances from the edge of the carriageway. The calculation results are presented in Table 2 .

Table 2. Indicators of environmental pollution of the roadside territories soil cover, taking into account the distance from the pollution source.

\begin{tabular}{|c|c|c|}
\hline $\begin{array}{c}\text { Distance from the edge } \\
\text { of the road. } \mathbf{m}\end{array}$ & $\begin{array}{c}\text { Total coefficient of } \\
\text { technogenic soil pollution } \\
\text { (Zc) }\end{array}$ & $\begin{array}{c}\text { Integral indicator of soil } \\
\text { pollution. taking into } \\
\text { account toxicity }(\boldsymbol{B})\end{array}$ \\
\hline 5 & 7.2 & 75 \\
\hline 25 & 5.3 & 78 \\
\hline 50 & 1.59 & 98 \\
\hline
\end{tabular}

According to [7], based on an indicative scale of soil pollution hazard in terms of the total pollution indicator $(\mathrm{Zc})$, the entire study area belongs to the permissible pollution category, where the Zc value does not exceed 16. The second integral indicator $(B)$ demonstrates insignificant pollution at a distance of $5 \mathrm{~m}$ from the edge of the road (75 points out of 100), and practically clean soil cover at a distance of $50 \mathrm{~m}$. When we assess the degree of danger of soil contamination for the most toxic element with the maximum content, the excess of the MPC was recorded for two elements of the 1st hazard class, lead and zinc. Thus, the 5meter zone belongs to the category of very strong pollution (2 MPC for lead, $1 \mathrm{MPC}$ for zinc) and the zone from 25 to $50 \mathrm{~m}$ belongs to the slightly contaminated (1,5 MPC for lead).

\section{Conclusions}

More than $50 \%$ of the land structure of the roadside territories of the Republic of Crimea is represented by agricultural land. It is legislated that during the construction and reconstruction of roads, it is necessary to build bypass roads around settlements. Despite this, there are a large percentage of settlements lands, which are adjacent to highways. This is due to the fact that the road network in Crimea was designed in the middle of the last century, when the technogenic impact was insignificant. Today, intensive motorization requires compliance with sanitary and hygienic standards and establishment of special land use regime to minimize environmental damage to roadside areas.

As a result of the studies, carried out, the elemental series of the accumulation of heavy metals in soils $\mathrm{Zn}>\mathrm{Pb}>\mathrm{Cu}>\mathrm{Co}>\mathrm{Cd}>\mathrm{Fe}$ was established. As the results of calculations show, the total coefficient of technogenic pollution $(\mathrm{Zc})$ is in the range from 0 to 16 , which characterizes the study area as unpolluted or tolerably polluted. The calculation of the integral indicator, taking into account the toxicity of the substance $(B)$, also demonstrates insignificant pollution in the zone of $0-25 \mathrm{~m}$ from the road edge, in the zone of $25-50 \mathrm{~m}$ the integral indicator is close to the background - 98 points out of 100. The excess of the MPC was recorded for two chemical elements of the 1st class hazards: zinc and lead. The content of other metals does not exceed background values. 
The presence of high concentrations of lead is associated with a cumulative effect during the operation of the road. Particular attention should be paid to zinc content, since a further increase in car traffic (especially in summer) contributes to a further increase in concentration of this metal not only in soil, but also in accumulation in plants and migration to aquatic environment. In addition, it is necessary to organize monitoring studies of soils, surface and ground waters of roadside areas in order to identify harmful substances that threaten population health.

\section{References}

1. G. Khodanov, A. Volnov, Scientific review 3, 92-99 (2019)

2. I. Medvedev, S. Derevyagin, Heavy metals in ecosystems (Rakurs, Saratov, 2017)

3. V. Pshenin, Proc. of the All-Russian sci. prac. seminar "Greening of road transport", IAELPS, 83-88 (2003)

4. K. Swaileh, R. Hussein, S. Abu-Elhoj, Arch. Environ. Contam. Toxicol. 47, 23-30 (2004)

5. J. Deska, et al., Polish J. of Environ. Stud. 20(2), 317-325 (2011)

6. Kh. Farooq Akbar, et al, Soil \& Water Res. 1(4), 158-163 (2006)

7. Endale Teju et al., Ethiop. J. Sci. 35(2), 81-94 (2012)

8. D. Pinsky, et al, Eurasian Journal of Soil Science 2, 59 - 68 (2013)

9. L. Xiaoxing, W. Iahui, S. Huiqing, R. Yi, Advanced Materials Research 955-959, 585588 (2014)

10. S. Sushkova, T. Minkina, I. Deryabkina (Turina), J. Soils Sediments 18, 2361-2367 (2018)

11. A. Martsev, O. Selivanov, E3S Web of Conf. 135 (2019) https://doi.org/10.1051/e3sconf/201913501047

12. E. Antonenko, A. Melnichuk, Scientific, and Publishing Center "Relevance.RF» 34, 84-86 (2020)

13. $M G$ 2.1.7.730-99 Methodological guidelines 2.1.7. Soil, clearing of populated areas, household and industrial waste, sanitary protection of soil. Hygienic assessment of soil quality in populated places, https://docs.cntd.ru/document/1200003852

14. V. Titova, M. Dabakhov, E. Dabakhova, Soil Sci., 1264-1267 (2004)

15. E. Ibrahimova, D. Balleieva, E. Aliyev, Ecology and noospherology 17, 113-121 (2006) 